\title{
Optimization of College English Teaching under the Environment of Quality Education
}

\author{
Xie Fang \\ Yunnan Technology and Business University \\ Yanglin Occupation and Education Industrial Zone \\ Kunming,Yunnan, 651701 China
}

\begin{abstract}
In order to meet the needs of talents in the new era for the state and society, college English teaching goal proposed by the Ministry of Education is to develop students' ability to use English. For this reason, college English teaching should change teaching philosophy, from the existing examination assessments "teacher-centered" to "studentcentered", improve the existing teaching methods, implement teaching methods of heuristic and seminar-style combination, and reform the present way of assessment, from the simple assessment into simple assessment and formative assessment combined so as to implement quality education.
\end{abstract}

Keywords- Quality education, teaching characteristics, English classroom, teaching optimization

\section{INTRODUCTION}

With the deepening of China's opening up, the community needs to have a certain level of English talent, especially those with strong English communication skills. To adapt to the new situation, to meet the needs of talents in the new era, college English teaching goal is to develop students' ability to use English, especially listening and speaking skills, so that they can use English in their future work and social interactions effectively for oral and written information exchange, while enhancing their self-learning ability, improve the overall cultural awareness, in order to meet the needs of social development and international exchange. To ensure that the teaching reform to get the desired results, the transformation from the examinationoriented education to quality education must be achieved and to establish quality-oriented education college English teaching mode.

College English teaching is a classroom educational activity with strong sense of theory and practice, carrying the responsibility to enhance students' self-learning ability, improves the comprehensive humanities, and an important quality value of education. College English teaching effectiveness depends not only on the level of teachers' professional knowledge, but also by teaching methods, the impact of teacher-student relationship and other nonintellectual factors. Therefore, it needs teachers' scientific and rational designs, creating a relaxed atmosphere in the classroom, focusing on utilization of science teaching methods, and establishing a harmonious relationship between teachers and students, through continuous optimization of the structure of college English teaching English teaching to enhance efficiency, and then to build a new model of quality education in English, and improve the quality of teaching in English education.

\section{QUALITY AND QUALITY EDUCATION}

Quality is a comprehensive concept that covers many aspects. Arguably, the quality refers to the individual's innate physiological and psychological characteristics and quality acquired through environmental education, usually divided into ideological quality, cultural and scientific qualities, and specific business qualities, such as physical and labor quality. Different times for talent quality requirements are different. As the factory produces products, school's students are the "product", the purpose of schooling is to develop a good "product", namely personnel to meet the needs of social development and social construction. This "product" is reflected in the quality of the talents. School teaching itself should make for students to develop the quality of education to cultivate the main perpetrator for the purpose of quality education. In the universities, the students' quality education mainly reflected in its ideological and cultural qualities and psychological quality, every subject should advocate for quality education.

The voice of quality education in the current education reform is the highest; implementation of quality education in college English teaching is entirely feasible. While students master Basic English language skills, strengthen their cultural quality, the quality of language education, improve their self-learning ability, through the analysis of language materials for students of political ideological and moral education, making them to become qualified personnel. Classroom teaching is undoubtedly the most direct and effective way to receive education for students, and the purpose decided that the English teaching should focus on training students' ability to use the English language, how to cultivate the ability of using English and implement quality education at the same time in the classroom. The goal of cultural quality and English teaching is cross-cultural communication, language is the carrier of culture, which in turn varies with cultural background and continue to develop. Quality language training, language training, includes voice quality basic knowledge, language skills and the use of 
English in cross-cultural communication skills. To develop self-learning ability, there is a saying: "Language is not taught." This sentence is not to deny the role of foreign language teachers, but to illustrate a crucial role in the process of learning a foreign language the student played. Ideological and moral cultivation, the ideological and moral qualities are among people's ethics, but also a necessary condition for social stability and harmonious development.

\section{FEATURES OF QUALITY EDUCATION}

In 2001 and 2004, two new curriculum have been developed and promulgated, added vitality to quality education, which is a product of the information age, both have some similarities with the overall development of education policy advocated in the 1950s, but also have significant differences in the early "examination-oriented education." Because the new curriculum standard of quality education is for all students under the education, examination-oriented education is focusing on the part of even a few students who can ascend to higher levels of education. Language is for communication. Peter Drucker in "post-socialist capital," has mentioned: "Knowledge is for using, rather than to the belly. A practice is more useful than the theory with a hundred words." Thankfully, the quality of education stressed that "to promote the comprehensive development of the quality of students, improve their human qualities, enhance practical ability and innovative spirit, and completely different from the only one-sided emphasis on the development of the written exam-oriented education.

Meanwhile, the quality education is to promote the implementation of human subjects, student-centered teaching, especially in the New Curriculum, it puts "to inspire and develop students' interest in learning, to enable students to build confidence, to develop good study habits and form an effective learning strategies, to develop self-learning ability and spirit of cooperation "in the first place. Unlike the past to meet the test, only put "master the basic knowledge of the language and basic skills" as the primary task of the syllabus.

\section{A. Moderate "open" teaching content}

Quality education is a "people-oriented" and "studentcentered" education, the content selection on full consideration of students' cognitive and emotional needs, and only when the students are taught to feel content with their needs and physical and mental condition coincides, this kind of content is most easily absorbed and internalized. In the content choice of classroom teaching, if temporarily give up the explanation on the part of the text information and language point on the surface, make they actively participate in the discussion of the text, put experience and knowledge into English teaching, then the text will enable students to form a deeper impression, and a deeper understanding of what they have learned.

\section{B. Interactive classroom discourse}

Classroom discourse has more special meaning for the English discipline, teaching is both language media, but also the content of teaching, the quantity and quality of teachers' English language and students' quantity of opportunities to use the language directly impact the results of students' language learning. In the classroom Quality-oriented education, it is common for speech acts such as conversation between teachers and students, classroom discourse is interactive, and its structure is also complex and diverse, so that students can participate through their own language classroom activities, strengthen understanding of the process, the expression of cognitive learning and emotional needs.

\section{Status AND PROBlems OF COLLEGE ENGLISH}

Years of examination-oriented education makes college English teaching not learn for learning, but learn for test. In the actual teaching, examination-oriented education is widespread, there are blind comparisons of schools focusing on the pass rate and excellent rate, while ignoring the students ability to apply, resulting in students' English practical ability.

College English teaching mode is single, old, making students lose interest in learning English, the lack of motivation to learn English, but also led to the emergence of "Dumb English" and so, over the years, teacher-centered and grammar-translation method occupy English teaching positions in our country as the absolute protagonist, but now, this phenomenon has not changed greatly. According to a survey conducted by Professor Su Dingfang show: More than $70 \%$ of teachers admitted that he is still using the teaching method of grammar-translation.

A very serious problem is the lack of teachers in college English teaching at the present. Teacher is a direct factor affecting teaching effectiveness, adequate high-quality teachers are important to ensure the quality of teaching in English, however, the overall quality of the current college English teachers in Chinese universities is not high, and the number is serious shortages.

The main organization form of English teaching is classroom teaching; classroom teaching is still the main way for students to learn English. Teaching inefficient, outdated teaching methods, the test flood, low teachers' quality are all problems. University students started going to school have high expectations for English learning in university, but through a stage of learning, whether teachers or students will soon fall into the trapping of "teaching to the test" . Overall, the students' enthusiasm showed a decreasing trend at the level of college.

\section{HOW TO OPTIMIZE CLASSROOM TEACHING}

\section{A. Aiming at college students to improve their learning}

Interest is the best teacher, so in order to achieve the independence of college students to learn English, we should stimulate their interest in learning English, so I think the primary task of the current major college English teaching reform is to achieve self-learning awareness and ability of college students.

\section{B. Aiming at the university education system to improve classroom organization}

Most students will spend valuable time in a variety of community activities or the various competitions, which led 
to spend very little time on the study of English course, therefore, for college English teaching, the college students fully grasping the English classroom learning time will become a key factor, the traditional mode of teachingoriented education is obviously not able to meet the needs of quality education, so students should be the centre of college English teaching methods.

\section{Aiming at English teaching materials to meet the needs of students}

Everything from reality, which is the basic principle of university teaching, Therefore, the choice of college English teaching materials should also insist on the reality principle, which is close to the daily life of college students and easy to memorize, in the preparation of teaching materials should also combine with real life, the social events in the same time period so that students will have resonance in the learning time, and improve interest in their study.

\section{Transforming starting point to create a democratic atmosphere and establish a good teacher-student relationship}

For a long time, teachers are starting from teaching; in order to achieve English class optimization, implementation of quality education, the English teacher should transform the starting point of classroom teaching to the student's learning. Teachers' teaching is for students' learning, classroom teaching should take student learning as a starting point to guide and inspire the students.

\section{E. Excavating training content of materials, penetrating moral education, and focusing on students' personality}

English is a strong ideological language science, English can be a direct reflection of people's thoughts and feelings and dissemination of social science and cultural knowledge. Psychological research shows that: Compared with intelligence, creativity affected more interests, hobbies, emotions, feelings, etc. Mining moral point of penetration in the materials in English teaching, training the students' quality and personality, can make students receive a good influence on the soul.

\section{F. Organizing colorful classroom activities to train students' ability}

In English teaching, activity is a bridge and link for twoway communication of the students and teachers. activities is the main channel to achieve communicative ability, improve the quality of students. Rich classroom activities can cultivate students' sense of innovation and creativity.

\section{CONCLUSION}

In summary, we can see that with the progress of the times and social development, the quality education placing the traditional exam-oriented education is a historical necessity. As a foreign language teacher, we should constantly learning and thinking, exploring connotation and characteristics of quality education and quality education teaching, striving to wide interpretation of the concept of teaching practice into our practical action. Only in this way will we be able to train more qualified personnel for the construction of the motherland. Quality education has been obtained a high degree of attention of our state and government, quality education has also been the concern of the whole society and the atmosphere of quality education are gradually forming at school.

Today the purpose of exploring the implementation of quality education in professional courses teaching is to bring quality education solidly implemented, to develop highquality talent in a new era for the needs of the country and to make our due contribution. Our educational front is experiencing a quality education as the center of unprecedented change. We have reason to believe that the current discussion and exploration of relevant quality education will promote more rapid development of China's English education reform and deepening of China's higher education career.

\section{REFERENCES}

[1] Liu Changjiang. College English Classroom Context ecological imbalance in the following information and Reconstruction [D]. Shanghai International Studies University, 2013.

[2] Chengui Qin. College English Teaching intercultural problems and countermeasures [D]. Shanghai International Studies University, 2014.

[3] Sui Xiaobing. Optimization of college English teaching [D] under the network environment. Shanghai International Studies University, 2013.

[4] Gu Shimin. Factor in college English courses to promote independent learning research [D]. Shanghai International Studies University, 2013.

[5] Yuli. College English teacher autonomy in curriculum implementation research: Perspective Courses creation of [D] Shanghai International Studies University, 2013.

[6] Li Ren.College English Teaching from the Perspective of Ecology [D]. Shanghai International Studies University, 2013.

[7] Liang Yulan. Multimedia College English classroom teaching and management [J]. Intellect,2013,28:168-169.

[8] Zhang Jiazheng. Philosophy of college English teaching reform culture [D]. Southwest University, 2010. 